\title{
Effect of Hydrogen Peroxide and Other Protease Inhibitors on Cryptosporidium parvum Excystation and In Vitro Development
}

\author{
Author(s): K. E. Kniel, S. S. Sumner, M. D. Pierson, A. M. Zajac , C. R. Hackney, R. Fayer, and D. S.
} Lindsay

Source: Journal of Parasitology, 90(4):885-888. 2004.

Published By: American Society of Parasitologists

DOI: http://dx.doi.org/10.1645/GE-203R1

URL: http://www.bioone.org/doi/full/10.1645/GE-203R1

BioOne (www.bioone.org) is a nonprofit, online aggregation of core research in the biological, ecological, and environmental sciences. BioOne provides a sustainable online platform for over 170 journals and books published by nonprofit societies, associations, museums, institutions, and presses.

Your use of this PDF, the BioOne Web site, and all posted and associated content indicates your acceptance of BioOne's Terms of Use, available at www.bioone.org/page/terms_of_use.

Usage of BioOne content is strictly limited to personal, educational, and non-commercial use. Commercial inquiries or rights and permissions requests should be directed to the individual publisher as copyright holder. 
, B. Goh, AND G. Prosperi-Porta. 2003. Duration and method of fixation affects the sensitivity of a digoxygenin-labelled DNA probe in detecting Kudoa thyrsites in Atlantic salmon skeletal muscle. Aquaculture 220: $157-164$.

, G. Prosperi-Porta, S. C. Dawe, and D. P. Barnes. 2003. Distribution, prevalence and severity of Parvicapsula minibicornis infections among anadromous salmonids in the Fraser River British Columbia, Canada. Diseases of Aquatic Organisms 54: 49-54.

Kent, M. L., J. Khattra, R. P. Hedrick, and R. H. Devlin. 2000. Tetracapsula renicola $\mathrm{n}$. sp. (Myxozoa: Saccosporidae); the PKX myxozoan-the cause of proliferative kidney disease of salmonids fishes. Journal of Parasitology 86: 103-111.

, D. J. Whitaker, AND S. C. Dawe. 1997. Parvicapsula minibicornis $\mathrm{n}$. sp. (Myxozoa, Myxosporea) from the kidney of sockeye salmon (Oncorhynchus nerka) from British Columbia, Canada. Journal of Parasitology 83: 1153-1156.

Raverty, S., D. Kieser, J. Bagshaw, and S. St-Hilaire. 2000. Renal infestation with Parvicapsula minibicornis in wild sockeye salmon from the Harrison and Adams rivers in British Columbia. Canadian Veterinary Journal 41: 317-318.

St-Hilaire, S., M. Boichuk, D. Barnes, M. Higgins, R. Devlin, R. WithleR, J. Khattra, S. Jones, AND D. Kieser. 2002. Epizootiology of Parvicapsula minibicornis in Fraser River sockeye salmon, Oncorhynchus nerka (Walbaum). Journal of Fish Diseases 25: 107120.

Stokes, N. A., AND E. M. Burreson. 1995. A sensitive and specific DNA probe for the oyster pathogen Haplosporidium nelsoni. Journal of Eukaryotic Microbiology 42: 350-357.

\title{
Effect of Hydrogen Peroxide and Other Protease Inhibitors on Cryptosporidium parvum Excystation and In Vitro Development
}

\author{
K. E. Kniel, S. S. Sumner, M. D. Pierson, A. M. Zajac ${ }^{\star}$, C. R. Hackney†, R. Fayerł, and D. S. Lindsay ${ }^{\star}$, Department of Food Science and \\ Technology, Virginia Tech, Blacksburg, Virginia 24061; *Virginia-Maryland Regional College of Veterinary Medicine, Virginia Tech, Blacksburg,

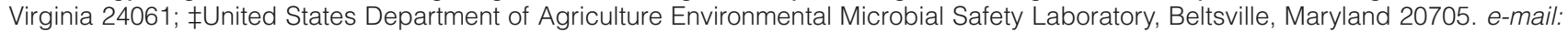
kniel@udel.edu

\begin{abstract}
This study was undertaken to observe the effects of hydrogen peroxide on Cryptosporidium parvum oocysts with respect to protease activity in comparison to known protease inhibitors. In assessing the possible mechanisms of action of hydrogen peroxide, treatment effectiveness was analyzed using 3 assays and the potential roles of proteases and cations were considered. Treatment of C. parvum oocysts with hydrogen peroxide inhibited protease activity up to $50 \%$ compared with untreated controls. Treatment of oocysts with chemicals that affect sulfhydryls, including $\mathrm{N}$-ethylmaleimide and dithiolthreitol, inhibited protease activity by $>90 \%$. Treatment of oocysts with these chemicals, along with the protease inhibitors, phenylmethylsulfonyl fluoride (PMSF), ethylenediamine-tetraacetic acid, and cystatin, inhibited protease activity as well as in vitro excystation and infection in a cell culture assay. Several mechanisms may result in the successful inhibition of infection and excystation by hydrogen peroxide treatment, including: oxidation of oocyst wall proteins or lipids, chelating of cations necessary for infection, or hydroxyl radical-induced DNA damage to sporozoites, or both.
\end{abstract}

Cryptosporidium parvum is an intestinal apicomplexan parasite, which can cause severe illness in immunocompetent individuals (Tzipori, 1988) and life-threatening disease in immunocompromised individuals (Current and Garcia, 1991) and malnourished children (Griffiths et al., 1994). Outbreaks of cryptosporidiosis result from water- and food-borne transmission of the small $(4-5 \mu \mathrm{m})$, environmentally resistant oocyst stage (Fayer et al., 2000). Fecal-borne C. parvum oocysts are infectious immediately on passage from the body. When ingested by a susceptible person or animal, oocysts pass to the intestine where the sporozoites that are held within the oocyst wall excyst, enter enterocytes, and generate a predetermined series of life cycle stages. Excystation (release of the sporozoites from the oocyst) may be mediated by a combination of internal and external effects that have not been thoroughly described. Cryptosporidium parvum excystation has been observed in vitro by incubation at $37 \mathrm{C}$; it is enhanced by preincubation in a low-pH suspension medium and by addition of trypsin and bile salts to the suspension medium (Fayer and Leek, 1984; Kato et al., 2001).

It has been proposed that specific proteases are involved in the excystation process and at least 1 step of the parasite invasion-infection process may be mediated by protease activity (Forney et al., 1996a, 1996b). These protease-mediated or protease-dependent mechanisms have been studied more extensively in related apicomplexan parasites, including Plasmodium knowlesi, Plasmodium falciparum, Eimeria tenella, and Eimeria vermiformis (Dluzewski et al., 1986; Adams and Bushell, 1988; Fuller and McDougald, 1990; Que et al., 2002). Protease-mediated events are believed to include host cell attachment (Adams and Bushell, 1988; Arroyo and Aldrete, 1989), host membrane penetration (Hadley et al., 1983; Fuller and McDougald, 1990), host protein degradation used for parasitic growth (Chappell and Dresden, 1986), tissue migration (Moda et al., 1988; McKerrow et al., 1990; Moda and Doenhoff, 1994a; Morris and Sakanari, 1995; Yenbuter and Scott, 1995), parasite development (Richer et al., 1993), and mechanisms used to fight and evade the host immune system (Maizels et al., 1993; Pupkis et al., 1986; Moda and Doenhoff, 1994b). Proteases, classified by the active group, are divided into 3 types: cysteine, serine, and metalloproteases. Because serine and cysteine proteinases increase in concentration during incubation at $37 \mathrm{C}$ before excystation, they are thought to function in excystation of $C$. parvum oocysts and cleavage of oocyst wall proteins (Forney et al., 1996a). Because the invasion process has been shown to be both pH- and metallodependent (Hamer et al., 1994), proteases may be involved in this process also.

Although C. parvum oocysts are resistant to disinfection with concentrations of chlorine that readily render bacteria and viruses nonviable, other oxidizing agents, including ozone and hydrogen peroxide, more readily inhibit viability (Vassal et al., 1998; Rennecker et al., 2001). Treatment of $C$. parvum oocysts with a low concentration of hydrogen peroxide, i.e., $0.03 \%$, inhibited excystation (Kniel et al., 2003). The amino acid cysteine is highly reactive and susceptible to oxidation. Cysteine-dependent enzymes are rendered inactive by loss of their free sulfhydryl group (reduced form), making cysteine proteases potential targets for chemotherapeutic attack. Hydrogen peroxide readily oxidizes sulfhydryl groups and could inhibit C. parvum excystation by affecting cysteine proteases previously identified as involved in excystation (Forney et al., 1996a).

The purpose of this study was to better understand the possible modes of action of hydrogen peroxide, including the action in relation to protease activity and that compared with known chemical inhibitors. The protease activity of hydrogen peroxide at concentrations known to effect oocyst development was compared with that of untreated oocysts along with protease-inhibiting chemicals. The following 3 assays were used for this analysis, i.e., an HCT-8 cell culture infectivity assay, an in vitro excystation assay, and an in vitro proteolytic activity assay. 
Cryptosporidium parvum oocysts (Beltsville isolate) were obtained from infected dairy calves and processed at the Environmental Microbial Safety Laboratory, United States Department of Agriculture, Beltsville, Maryland (Fayer et al., 2001). Oocysts were purified from fecal material as described previously (Kilani and Sekla, 1987) and quantified with the aid of a hemacytometer. Cryptosporidium parvum oocysts (5 $\times 10^{5}$ per treatment) were treated with $0.525 \%$ sodium hypochlorite at $4 \mathrm{C}$ for less than $5 \mathrm{~min}$ and washed twice with Hanks Balanced Salt Solution (HBSS; Mediatech, Cellgro, Herndon, Virginia). Oocysts were then treated with protease inhibitors or related chemicals at specified concentrations for $30 \mathrm{~min}$ at $22 \mathrm{C}$ or with specified concentrations of hydrogen peroxide in water for $2 \mathrm{hr}$ at $4 \mathrm{C}$. Oocysts were washed twice with HBSS after treatment. Oocysts washed with sodium hypochlorite and HBSS served as controls. Protease inhibitors and sulfhydryl reagents including hydrogen peroxide (Sigma, St. Louis, Missouri), $N$ ethylmaleimide (NEM, Sigma), dithiolthreitol (DTT, Sigma), ethylenediamine-tetraacetic acid (EDTA), cystatin (Sigma), and phenylmethylsulfonyl fluoride (PMSF, Sigma) were dissolved in phosphate-buffered saline (PBS). PMSF was first dissolved in dimethylsulfoxide (DMSO) and diluted to desired concentrations in PBS. Control assays were prepared in both PBS and DMSO (final concentrations equal to those of diluted PMSF).

Infection was analyzed using Human ileocecal adenocarcinoma cells (HCT-8 cells) (ATCC CCL-244, American Type Culture Collection, Manassas, Virginia), which were maintained in Roswell Park Memorial Institute 1640 medium (Mediatech Cellgro) supplemented with L-glutamine (300 mg/L; Mediatech Cellgro) and $\mathrm{N}$-2-hydroxythylpiperazine$N^{\prime}$-2-ethane-sulfonic acid ( $25 \mathrm{mM}$; Mediatech Cellgro). For normal cell maintenance medium was supplemented with $5 \%$ fetal bovine serum (Biofluids Inc., Rockville, Maryland) and increased to $10 \%$ fetal bovine serum for parasite infection (Upton et al., 1995). Stock HCT-8 cells were maintained in $75-\mathrm{cm}^{2}$ tissue culture flasks in a $5 \% \mathrm{CO}_{2}$ atmosphere at $37 \mathrm{C}$ and $100 \%$ humidity and passaged every 3-5 days. Cells were lifted from the surface with a solution of $0.25 \%(\mathrm{wt} / \mathrm{v})$ trypsin and 0.53 mM EDTA in PBS (Mediatech Cellgro). Trypsinization required 10- to 12-min incubation in the solution at $37 \mathrm{C}$ to assist disruption of the cell monolayer. The cells were collected and pelleted by centrifugation for $10 \mathrm{~min}$ at $1,000 \mathrm{~g}$, resuspended in maintenance medium, and split 1: 10. Cell viability was assessed with trypan blue exclusion $(0.02 \%$ in PBS) and cells counted with a hemacytometer.

For inoculation, HCT-8 cells were seeded on sterile $22-\mathrm{mm}^{2}$ glass coverslips in six-well cluster plates (Corning, Corning, New York) at 1 $\times 10^{6}$ cells per well and grown to $\sim 95 \%$ confluence in maintenance medium (48 hr). Cryptosporidium parvum oocysts were treated as stated above. For infection of monolayers and before inoculation with oocysts, the maintenance medium was removed and $3 \mathrm{ml}$ growth medium added to each well in six-well cluster plates. Cells were then incubated with treated or nontreated (positive control) oocysts $\left(10^{6}\right.$ oocysts in $1 \mathrm{ml}$ growth medium) for $120 \mathrm{~min}$. After $2 \mathrm{hr}$, unexcysted oocysts, oocyst walls, and other materials that may have been liberated from the excysted oocysts were removed from the monolayers by washing each inoculated well twice with HBSS. Cells in cluster plates were then placed back in the incubator for $48 \mathrm{hr}$ with $3-4 \mathrm{ml}$ maintenance medium per well.

Parasite infection was assessed $48 \mathrm{hr}$ after infection using an immunohistochemistry stain (Phelps et al., 2001). Coverslips in six-well cluster plates were fixed with $100 \%$ methanol for $20-30 \mathrm{~min}$ and washed twice for 5 min each with PBS. Coverslips were removed from cluster plates and processed on slides, first with a rabbit anti-C. parvum primary antibody followed by a biotinylated anti-rabbit secondary antibody and an avidin biotinylated complex (Vectastain ABC Kit, Vector Laboratories, Burlingame, California). Life cycle stages were observed with an immunoperoxidase stain using hydrogen peroxide (Sigma), diaminobenzidine tetrahydrochloride (Sigma), with hematoxylin (Fisher Scientific, Pittsburgh, Pennsylvania) used as a counterstain. Treatment effectiveness was determined by counting the number of positive fields (any field containing a C. parvum life cycle stage) out of 100 total fields observed with $\times 400$ magnification. Each individual experiment was performed in triplicate. Percent reduction compared with untreated oocysts was determined using the following equation: ([Control - Treated]/Control) $\times 100$. Data are expressed as the mean percent inhibition followed by the standard deviation.

Cryptosporidium parvum homogenate was prepared from treated and

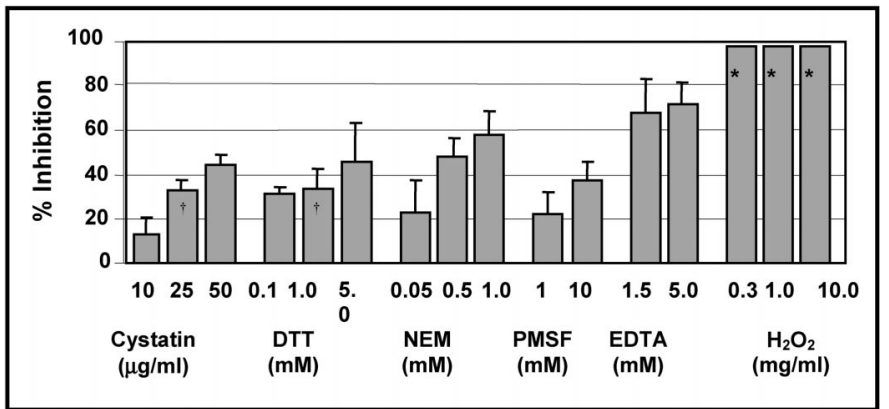

FIGURE 1. Inhibition of development in HCT-8 cell monolayers after exposure of $C$. parvum oocysts to protease inhibitors. Percent inhibition of infection by treated oocysts was determined compared with control oocysts and represented by an average from 3 replicate experiments with standard deviation shown. No viable life stage was observed in cells infected with oocysts treated with hydrogen peroxide $\left(^{*}\right)$. Treatments were significantly different from each other with 2 exceptions (as indicated by the same symbols): hydrogen peroxide treatments; $1.0 \mathrm{mM}$ DTT and $25 \mu \mathrm{g} / \mathrm{ml}$ cystatin.

untreated oocysts as described (Forney et al., 1996a). Oocysts $\left(10^{5}\right)$ suspended in $1 \mathrm{ml}$ of liquid were snap frozen in liquid nitrogen after treatment, then thawed in a $37 \mathrm{C}$ water bath twice, and then sonicated $6 \times 1 \mathrm{~min}$ in an ice-cooled water bath sonicator to produce the homogenate (Forney et al., 1996a). The homogenate was used in an assay for protease activity using azocasein (Sigma) as the substrate (Plantner, 1991; Forney et al., 1996a). Briefly, $2 \mathrm{mg} / \mathrm{ml}$ azocasein in $100 \mathrm{mM}$ sodium phosphate buffer was prewarmed to $37 \mathrm{C}$ for $15 \mathrm{~min}$, and 50 $\mu l$ of C. parvum homogenate added, incubated at $37 \mathrm{C}$ for $10-11 \mathrm{hr}$. After incubation, $40 \mu \mathrm{l}$ of cold $50 \%$ trichloroacetic acid (Sigma) was added to each sample to precipitate any undigested azocasein. Samples were incubated on ice for $60 \mathrm{~min}$ and then centrifuged at 2,000 $\mathrm{g}$ for $10 \mathrm{~min}$. The supernatant was removed to a microtiter plate already containing $200 \mu$ of $10 \mathrm{~N} \mathrm{NaOH}$ in each well. Absorbance was measured at $450 \mathrm{~nm}$ with an automated microtiter plate reader (Bio-Tek Instruments, Winooski, Vermont). Diluted trypsin was used as a control, as suggested by Forney et al. (1996a). Protease activity readings from treated and untreated oocysts were compared and the percent inhibition determined.

For excystation, $1 \times 10^{5} \mathrm{C}$. parvum oocysts were washed and treated as those used for cell culture infectivity assays described above. Then, oocysts were incubated in $0.75 \%$ taurochloric acid (Sigma) for $30 \mathrm{~min}$ at $37 \mathrm{C}$. The excystation solution was observed at $\times 400$ and $\times 1,000$ magnification using differential interference contrast microscopy (DIC). A total of 100 shells and oocysts was counted. Samples were evaluated in triplicate. Oocysts containing sporozoites were considered unexcysted. Oocysts containing no sporozoite, also called shells, was considered excysted. The extent of excystation was calculated by the Woodmansee method (Woodmansee, 1987; Finch et al., 1993): excystation $=([$ oocysts excysted/total oocysts counted] $\times 100$ ).

Data from individual experiments were considered independent and were performed at least in triplicate. Experiments and controls were analyzed for significant differences using PROC GLM in SAS statistical software (SAS Institute, Cary, North Carolina). Effects of each treatment on parasite viability were considered to be significant when $P<$ 0.05 . Treatments were separated using Tukeys test for significant differences.

HCT-8 cells support complete development of $C$. parvum (Upton et al., 1995) and were found to mimic human infection more closely than animal infection assays. The percent inhibition of cell culture infectivity by various treatments was observed and compared with infection with untreated oocysts (Fig. 1). No developmental life cycle stage was observed after oocysts were treated with any concentration of hydrogen peroxide tested ( $2 \mathrm{hr}, 4 \mathrm{C}$ ). Inhibition of in vitro development after treatment of oocysts with EDTA was closest to that caused by hydrogen peroxide, with only a few developing stages observed. EDTA chelates cations $\left(\mathrm{Ca}^{2+}\right)$ and inhibits metalloproteases (Nesterenko et al., 1995). Hydrogen peroxide may disrupt intracellular calcium levels (Lipton and 
TABLE I. Effect of protease inhibitors on Cryptosporidium parvum oocysts indicated by in vitro protease activity.

\begin{tabular}{lcc}
\hline $\begin{array}{c}\text { Chemical } \\
\text { inhibitor }\end{array}$ & Concentration & \% Inhibition (SD) \\
\hline $\mathrm{H}_{2} \mathrm{O}_{2}$ & $0.3 \mathrm{mg} / \mathrm{ml}$ & $24.1 \S(1.53)$ \\
& $0.5 \mathrm{mg} / \mathrm{ml}$ & $40.4 \ddagger(5.94)$ \\
$\mathrm{NEM}$ & $10 \mathrm{mg} / \mathrm{ml}$ & $47.7 \ddagger(5.09)$ \\
& $1.0 \mathrm{mM}$ & $90.4 \dagger(17.1)$ \\
DTT & $5.0 \mathrm{mM}$ & $98.4 *(6.36)$ \\
Cystatin & $5.0 \mathrm{mM}$ & $90.8^{* \dagger(12.2)}$ \\
EDTA & $50 \mathrm{mg} / \mathrm{ml}$ & $88.8 \dagger(7.56)$ \\
PMSF & $1.5 \mathrm{mM}$ & $40.1 \ddagger(5.43)$ \\
\hline
\end{tabular}

The average above was obtained from 3 replicate experiments. Treatments with the same symbol were not significantly different from each other $(P<0.05)$

Nicotera, 1998), which may result in the reduced infection observed because calcium is necessary for proper cell invasion by $C$. parvum (Hamer et al., 1994; Upton et al., 1995). Treatments are significantly different from each other $(P<0.05)$, with 2 exceptions: $(1)$ hydrogen peroxide treatments are identical to each other regardless of concentration and (2) inhibition by $1.0 \mathrm{mM}$ DTT and $25 \mu \mathrm{g} / \mathrm{ml}$ cystatin was not significantly different $(P>0.05)$. DTT reduces sulfhydryls and can inhibit cysteine proteases at relatively high concentrations $(5 \mathrm{mM})$, whereas cystatin is a known cysteine protease inhibitor.

Table I shows the percent inhibition resulting from chemical treatment of oocysts. Protease activity was significantly reduced in homogenates prepared from oocysts that were chemically treated compared with those prepared from oocysts treated with HBSS.

Findings in this study, in which oocysts were exposed to protease inhibitors, appear to parallel those in which oocyst homogenates were exposed to inhibitors (Forney et al., 1996a). Inhibition levels were similar for oocysts treated with $10 \mathrm{mM}$ PMSF, a serine protease inhibitor, and those treated with cysteine protease inhibitors (NEM, DTT, cystatin). Both serine and cysteine proteinases are believed to be associated more with the sporozite outer membrane than with the oocyst membranes (Powers et al., 1993; Okhuysen et al., 1996; Nesterenko et al., 1995). Exposure to PMSF results in an inhibition of $90.3 \%$, which suggests that some chemicals, such as PMSF, may act within hypochloritepermiabilized oocysts although no statistical difference was observed between oocysts that received the $<5$-min pretreatment and those that did not (data not shown). Inhibition by NEM $(5.0 \mathrm{mM})$ and DTT $(5.0$ $\mathrm{mM}$ ) were similar, and both treatments affect sulfhydryls and inhibit cysteine protease activity. Inhibition of protease activity by hydrogen peroxide $(0.5$ and $10 \mathrm{mg} / \mathrm{ml})$ was similar to that by EDTA $(1.5 \mathrm{mM})$. Both chemicals may inhibit sporozoite activity by chelating calcium ions.

Sporozoites did not spontaneously excyst after oocysts were chemically treated before incubation with taurochloric acid at $37 \mathrm{C}$ for 30 min. Table II shows the extent of excystation after oocysts were treated with inhibitory chemicals. The corresponding log reduction was determined from the extent of excystation among control oocysts $(89 \pm 5.0)$. Intact oocysts, shells, and sporozoites were observed with DIC microscopy under $\times 1,000$ magnification. Sporozoites from oocysts treated with hydrogen peroxide did not show any type of motion, i.e., gliding or flexing, whereas untreated controls were moving. Oxygen radicals generated from the decomposition of hydrogen peroxide may have penetrated the oocyst wall and damaged the pellicle or subcellular organelles of the sporozoites. Sporozoites derived from oocysts treated with inhibitory compounds other than hydrogen peroxide were seen moving and showed no visible physical effect of damage. The extent of excystation among treated oocysts differed significantly from one another, with few exceptions; no difference was found among hydrogen peroxide treatments and $5.0 \mathrm{mM}$ NEM versus $10 \mathrm{mM}$ PMSF did not differ significantly. EDTA $(1.5 \mathrm{mM})$ inhibited excystation by $70 \%$, close to the inhibition by hydrogen peroxide. Exposure of oocysts to EDTA and hydrogen peroxide also significantly reduced or completely inhibited development in cell cultures (Fig. 1). The cysteine protease inhibitor
TABLE II. Effect of protease inhibitors on Cryptosporidium parvum oocysts indicated by in vitro excystation.

\begin{tabular}{lccc}
\hline $\begin{array}{c}\text { Chemical } \\
\text { inhibitor } \\
\text { reduction }\end{array}$ & Concentration & $\begin{array}{c}\text { Excystation } \\
\text { (SD) }\end{array}$ & $\log _{10}$ \\
\hline $\mathrm{H}_{2} \mathrm{O}_{2}$ & $0.3 \mathrm{mg} / \mathrm{ml}$ & $24.4 \|(5.2)$ & 0.56 \\
& $0.5 \mathrm{mg} / \mathrm{ml}$ & $22.2 \|(2.5)$ & 0.60 \\
& $10 \mathrm{mg} / \mathrm{ml}$ & $17.5 \|(6.3)$ & 0.70 \\
$\mathrm{NEM}$ & $1.0 \mathrm{mM}$ & $56.7 \ddagger(6.8)$ & 0.19 \\
& $5.0 \mathrm{mM}$ & $24.5 \|(2.0)$ & 0.56 \\
DTT & $5 \mathrm{mM}$ & $68.2 *(7.5)$ & 0.11 \\
Cystatin & $50 \mathrm{mg} / \mathrm{ml}$ & $61.9 \dagger(3.0)$ & 0.15 \\
EDTA & $1.5 \mathrm{mM}$ & $30.7 \S(6.4)$ & 0.46 \\
PMSF & $10 \mathrm{mM}$ & $21.0 \|(4.1)$ & 0.62 \\
\hline
\end{tabular}

The average above was obtained from 3 replicate experiments. Treatments with the same symbol were not significantly different from each other $(P<0.05)$.

cystatin did not significantly affect excystation, supporting previous observations (Forney et al., 1996a).

Results of this study indicate that hydrogen peroxide at these concentrations penetrates or affects the oocyst wall so that sporozoites are rendered nonviable. Concentrations used were chosen on the basis of food additive guidelines and their potential for use in food products without altering the original food flavor (FDA, 2001; Kniel et al., 2003). After comparison of the inactivation of cell culture infection, protease activity, and excystation with known sulfhydryl- (NEM, DTT, cystatin) and protease (PMSF, EDTA)-reactive agents, the mechanism of action by hydrogen peroxide still is not clear; however, 2 possibilities are suggested, i.e., sulfhydryl oxidation of proteins on the oocyst surface, which may be combined with lipid oxidation, or alteration in the movement of cations. Alternatively, hydrogen peroxide may oxidize cysteine proteases necessary for oocyst wall maintenance thereby reducing wall strength and lessening oocyst viability. Continuing research in this area may seek to provide information on the potential roles of chemical cations and proteases within the mechanisms of oocyst excystation and infection.

This project was supported in part by CSREES USDA Special Food Safety Grant 98-34382-6916, VPI\&SU HATCH project 135563, and a New Initiative Grant from the Virginia-Maryland Regional College of Veterinary Medicine. Cryptosporidium parvum antibody was provided courtesy of C. Dykstra, Auburn University, Auburn, Alabama.

\section{LITERATURE CITED}

AdAms, J. H., AND G. R. Bushell. 1988. The effect of protease inhibitors on Eimeria vermiformis invasion of culcutured cells. International Journal for Parasitology 18: 683-685.

ARROYO, R., AND J. AlDRETE. 1989. Trichomonas vaginalis surface proteinase activity is necessary for parasite adherence to epithelial cells. Infection and Immunity 57: 2991-2997.

Chappell, C., AND M. Dresden. 1986. Schistoma mansoni: Proteinase activity of "hemoglobinase" from the digestive tract of adult worms. Experimental Parasitology 61: 160-167.

Current, W. L., and L. S. Garcia. 1991. Cryptosporidiosis. Clinical Microbiology Reviews 4: 325-358.

Dluzewski, A. R., K. Rangachari, R. J. M. Wilson, and W. B. GratZER. 1986. Plasmodium falciparum: Protease inhibitors and inhibition of erythrocyte invasion. Experimental Parasitology 62: 416422.

FAYER, R., AND R. G. LEEK. 1984. The effects of reducing conditions, medium, $\mathrm{pH}$, temperature, and time on in vitro excystation of Cryptosporidium. Journal of Protozoology 31: 567-569.

, U. Morgan, AND S. J. Upton. 2000. Epidemiology of Cryptosporidium: Transmission, detection, and identification. International Journal for Parasitology 30: 1305-1322.

, J. M. Trout, L. Xiao, U. M. Morgan, A. A. Lai, and J. P. DubeY. 2001. Cryptosporidium canis sp. from domestic dogs. Journal of Parasitology 87: 1415-1422. 
Finch, G. R., E. K. Black, L. Gyurek, and M. Belosevic. 1993. Ozone inactivation of Cryptosporidium parvum in demand-free phosphate buffer determined by in vitro excystation and animal infectivity. Applied and Environmental Microbiology 59: 4203-4210.

Food AND DRUG Administration (FDA). 2001. Code of Federal Regulations. 21 CFR 181.1366.

Forney, J. R., S. YAnG, And M. C. Healey. 1996a. Protease activity associated with excystation of Cryptosporidium parvum oocysts. Journal of Parasitology 82: 889-892. AND 1 1996b. Efficacy of serine protease inhibitors against Cryptosporidium parvum infection in a bovine fallopian tube epithelial cell culture system. Journal of Parasitology 82: 638-640.

Fuller, A. L., AND L. R. McDougald. 1990. Reduction in cell entry of Eimeria tenella (Coccidia) sporozoites by protease inhibitors, and parial characterization of proteolytic activity associated with intact sporozoites and merozoites. Journal of Parasitology 76: 464467.

Griffiths, J. K., R. Moore, S. Dooley, G. T. Keusch, and S. Tzipori. 1994. Cryptosporidium parvum infection of Caco-2 cell monolayers induces an apical monolayer defect, electively increases transmonolayer permeability, and causes epithelial cell death. Infection and Immunity 62: 4506-4514.

Hadley, T., M. Aikawa, And L. H. Miller. 1983. Plasmodium knowlesi: Studies on invasion of rhesus erythrocytes by merozoites in the presence of protease inhibitors. Experimental Parasitology 55: 306-311.

Hamer, D. H., H. Ward, S. Tzipori, E. A. Pereira, J. P. Alroy, and G. T. KeUsCH. 1994. Attachment of Cryptosporidium parvum sporozoites to MDCK cells in vitro. Infection and Immunity 62: 2208 2213.

Kato, S., M. B. Jenkins, W. C. Ghiorse, and D. D. Bowman. 2001. Chemical and physical factors affecting the excystation of Cryptopsoriidum parvum oocysts. Journal of Parasitology 87: 575-581.

Kilani, R. T., AND L. SeKla. 1987. Purification of Cryptosporidium oocysts and sporozoites by cesium chloride and percoll gradients. American Journal of Tropical Medicine and Hygiene 36: 505-508.

Kniel, K. E., S. S. Sumner, C. R. Hackney, M. D. Pierson, A. M Zajac, D. A. Golden, R. FAyer And D. S. Lindsay. 2003. Effect of organic acids and hydrogen peroxide on Cryptosporidium parvum viability in fruit juices. Journal of Food Protection 66: 16501657.

Lipton, S. A., AND P. Nicotera. 1998. Calcium, free radicals and excitotoxins in neural apoptosis. Cell Calcium 23: 165-171.

Maizels, R. M., D. A. P. Bundy, M. E. Selkirk, D. F. Smith, And R. M. ANDERSON. 1993. Immunological modulation and evasion by helminth parasites in human populations. Nature 365: 797-805.

McKerrow, J. H., P. Brindley, M. Brown, A. A. Gam, C. Staunton, AND F. A. NEVA. 1990. Strongyloides stercoralis: Identification of a protease that facilitates penetration of the skin by the infective larvae. Experimental Parasitology 70: 134-143.

ModA, J., AND M. J. DoEnHOFF. 1994a. Complex formation of human alpha-1-antitrypsin with components in Schistoma mansoni cercariae. Parasite Immunology 16: 447-450.

, AND - 1994b. Schistosoma mansoni host-parasite relationship: Interaction of contrapsin with adult worms. Parasitology 96: 99-109.

, V. Parikh, J. Gauldie, And M. J. Doenhoff. 1988. An association between schistosomes and contrapsin, a mouse serine protease inhibitor (serpin). Parasitology 96: 99-109.

Morris, S. R., AND J. A. SAKANARI. 1995. Characterization of the serine protease inhibitor from the tissue-penetrating nematode Anisakis simplex. Journal of Biological Chemistry 269: 27650-27656.

Nesterenko, M. V., M. Tilley, And S. J. Upton. 1995. A metallodependent cystein proteinase of Cryptosporidium parvum associated with the surface of sporozoites. Microbios 83: 77-88.

Okhuysen, P. C., C. L. Chappell, C. Kettner, and C. R. Sterling. 1996. Cryptosporidium parvum metalloaminopeptidase inhibitors prevent in vitro excystation. Antimicrobial Agents and Chemotherapy 40: 2781-2784.

Phelps, K. K., D. S. Lindsay, S. S. Sumner, and R. Fayer. 2001 Immunohistochemistry based assay to determine the effects of treatments on Cryptosporidium parvum viability. Journal of Eukaryotic Microbiology 49: 40S-41S.

Plantner, J. J. 1991. A microassay for proteolytic activity. Analytical Biochemistry 195: 129-131.

Pupkis, M. F., L. Tetley, AND G. H. CoOmBs. 1986. Leishmania mexicana: Amastigote hydrolase in unusual lysosomes. Experimental Parasitology 62: 29-39.

Que, X., L. S. Brien, P. Perkins, S. Herdman, K. Hirata, B. E. Torian, H. Rubin, J. H. McKerrow, and S. L. Reed. 2002. Cystein proteinases from distinct cellular compartments are recruited to phagocytic vesicles by Entamoeba histolytica. Molecular and Biochemical Parasitology 119: 23-32.

Rennecker, J. L., J. Kim, B. Corona-Vasquez, and B. J. Marinas. 2001. Environmental Science and Technology 35: 2752-2757.

Richer, J. K., W. G. Hunt, J. A. SAKanari, And R. B. Grieve. 1993 Dirofilaria immitis: Effect of fluoromethyl ketone cysteine protease inhibitors on the third- to fourth-stage molt. Experimental Parasitology 76: 221-231.

TzIPORI, S. 1988. Cryptosporidiosis in perspective. Advances in Parasitology 27: 63-129.

Upton, S. J., M. Tilley, AND D. B. Brillhart. 1995. Effects of select medium supplements on in vitro development of Cryptosporidium parvum in HCT-8 cells. Journal of Clinical Microbiology 33: 371375 .

Vassal, S., L. FAvennec, J. BAllet, And P. Brasseur. 1998. Hydrogen peroxide gas plasma sterilization is effective against Cryptosporidium parvum oocysts. American Journal of Infection Control 26: $136-138$.

Woodmansee, D. B. 1987. Studies of in vitro excystation of Cryptosporidium parvum from calves. Journal of Protozoology 34: 298402.

Yenbuter, P., AND A. L. ScOtT. 1995. Molecular cloning of a serine proteinase inhibitor form Brugia malayi. Infection and Immunity 63: 1745-1753. 